models will facilitate comparison of actual behavior with existing guidelines.

Prehosp. Disaster Med. 2019;34(Suppl. 1):s64-s65

doi:10.1017/S1049023X19001432

Health Sector Preparedness During the Eid-al-Fitr Homecoming Across Indonesia in 2017 Miss. Madelina Ariani ${ }^{1}, M r$. Yurianto Achmad ${ }^{2}$, Mr. Kamarruzzaman Kamarruzzaman ${ }^{2}$, Mrs. Ina Agustina ${ }^{2}$, Mrs. Bella Donna ${ }^{1}, M r$. Hendro Wartatmo ${ }^{1}$

1. Center for Health Policy and Management, Faculty of Medicine, Public Health, and Nursing, Universitas Gadjah Mada, Yogyakarta, Indonesia

2. Health Crisis Center, Ministry of Health, Jakarta, Indonesia

Introduction: Indonesia's road traffic fatality rate stands at 15.3 per 100,000 people, compared to 17 in the Southeast Asia region. Traffic fatalities are predicted to increase by $50 \%$, becoming the third leading contributor to the global burden of disease by 2020 . Indonesian police reported that 575 people died and 2,742 road accidents occurred during Eid-al-Fitr 2015. The problem is increasing rapidly in Indonesia, particularly during Ramadan. Policy makers need to recognize this growing problem as a public health crisis to prevent mass casualty incidents.

Aim: To assess the health system preparedness with regard to road traffic accidents during 2017 Eid-al-Fitr homecoming in West Java, Central Java, East Java, and Lampung.

Methods: The project started with an interview and observation followed by stakeholder analysis to assess the level of preparedness. This qualitative and quantitative research was conducted one month prior to Eid-al-Fitr homecoming 2017. The instruments were evaluated for policy, organization, communication, procedure, contingency plan, logistics, facility and human resources, financing, monitoring, evaluation, coordination, and socialization.

Results: The levels of preparedness were moderate (B) for West Java, East Java, and Lampung, but high (A) for Central Java. Levels of preparedness based on district health office indicators were high for coordination, but low for a contingency plan. Levels of preparedness based on hospitals and primary health care were high for logistics and human resources, but low for a contingency plan and financing.

Discussion: The findings indicated a moderate level (B) of health sector preparedness. Benchmark information from this research will provide information for further training in contingency planning, particularly for the district health office.

Prehosp. Disaster Med. 2019;34(Suppl. 1):s65

doi:10.1017/S1049023X19001444

Impact of Road Safety Laws in Colombia on Road Traffic Collision Fatalities and Injuries

Dr. Killiam A. Argote ${ }^{1,2}$, Dr. Michael S Molloy ${ }^{1,3}$, Dr. Alexander Hart ${ }^{1,2}$, Amalia Voskanyan ${ }^{1,2}$, Dr. Ritu R Sarin ${ }^{1,2}$, A Prof. Gregory R Ciottone ${ }^{1,2}$
1. BIDMC Fellowship in Disaster Medicine, Boston, United States

2. Department of Emergency Medicine, Beth Israel Deaconess Medical Center, Boston, United States

3. University College Dublin, Belfield, Dublin, Ireland

Introduction: Road traffic collisions (RTC) are the leading cause of preventable death among those aged 15-29 years worldwide. More than 1.2 million lives are lost each year on roads. Ninety percent of these deaths take place in low- and middleincome countries. The General Assembly of the United Nations (UN) proclaimed the period from 2011-2020 the "Decade of Action for Road Safety," with the objective of stabilizing and reducing the number of deaths by $50 \%$ worldwide. In this context, the government of Colombia established the National Road Safety Plan (PNSV) for the period 2011-2021 with the objective of reducing the number of fatalities by $26 \%$. However, the effectiveness of road safety policies in Colombia is still unknown.

Aim: To evaluate the effect of road safety laws on the incidence of RTC, deaths, and injuries in Colombia.

Methods: RTC data and fatality numbers for the time period of January 1, 2010, to December 31, 2017, were collated from official Colombian governmental publications and analyzed for reductions and trends related to the introduction of new road safety legislation.

Results: Data analysis are expected to be completed by January 2019.

Discussion: RTC remains the leading preventable cause of death in Colombia despite the PNSV. Data is being mined to determine the trends of these rates of crashes and fatalities, and their relation to the introduction of national traffic laws. Overall, while the absolute numbers of RTC and deaths have been increasing, the rate of RTC per 10,000 cars has been decreasing. This suggests that although the goals of the PNSV may not be realized, some of the laws emanating from it may be beneficial, but warrant further detailed analysis.

Prehosp. Disaster Med. 2019;34(Suppl. 1):s65

doi:10.1017/S1049023X19001456

\section{A New Strategy for Swiftwater Rescue from Roadways during Urban and Small Stream Flash Flooding Dr. David Jaslow ${ }^{1}, M r$. Derek Zecher ${ }^{1}, M r$. Ryan Synnestvedt ${ }^{1}$, Mr. Kevan Melly', Dr. Ryan Overberger ${ }^{3}$ \\ 1. Bryn Athyn Fire Company, Bryn Athyn, United States \\ 2. Huntingdon Valley Fire Company, Huntingdon Valley, United States \\ 3. Einstein Medical Center, Philadelphia, United States}

Introduction: The swiftwater rescue (SWR) concept of operations (CONOPS) is to access as many victims as quickly as possible using strategies and tactics that maximize safety and minimize risk to all involved. "Reach, throw, row, go" has defined the primary water rescue strategy for $50+$ years. However, this paradigm, originally designed for rescue from swimming pools, ponds and lakes, slow-moving rivers, and the ocean, is not conducive to SWR incidents involving 
submerged vehicles, which is the most common scenario during urban and small stream flash flooding.

Aim: To present a new SWR strategy for urban and small stream flood response.

Methods: Water rescue strategies and tactics were mapped against the SWR CONOPS to determine which ones are most likely to be successful in the rescue of victims trapped in submerged vehicles.

Results: Rescue should be attempted via high water vehicles (HWVs) whenever possible, followed by watercraft and "go rescues" using advanced line systems techniques and/or tethered rescuers, dependent on incident characteristics. Positioning HWVs at the incident site permits rescuers to access victims quickly from the rear or sides of the vehicle, thereby reducing rescuer time in floodwaters. Multiple sequential rescues can be made since victims are held and medically monitored in the cargo area rather than transporting them to shore individually.

Discussion: SWR from submerged vehicles is unique among emergency incidents because neither shelter-in-place nor selfevacuation are tenable options until the water recedes. "Reach" and "throw" rescue attempts are only possible if the victim is close to shore. Watercraft operations, whether motorized or manually pulled, can be technically complex, require numerous rescuers, and typically take 30-60 minutes per vehicle. Use of HWVs meets the CONOPS for SWR on flooded roadways since this strategy facilitates the rescue of multiple victims quickly while reducing the time rescuers spend in the water.

Prehosp. Disaster Med. 2019;34(Suppl. 1):s65-s66

doi:10.1017/S1049023X19001468 